\title{
Statistical Analysis of the Most Influential Cryptocurrencies
}

\author{
Višnja Jurić \\ University College "Effectus, for Law and Finance", Croatia \\ Vanja Šimičević \\ University of Zagreb, Department of Croatian Studies, Croatia \\ Domagoj Kajba \\ Zagreb School of Economics and Management, Croatia
}

\begin{abstract}
A comparison of the most 30 influential cryptocurrencies has been made, based on the "CoinMarketCap" web page. Over the last few years, an increasing number of the world's population is investing in the cryptocurrency market. The emphasis is placed on Bitcoin, which is the absolute leader on this market. The difference between electronic money and virtual currency is explained, followed by the history of crypto values. Finally, the statistical analysis of the most influential cryptocurrencies, during the last year, will be presented.
\end{abstract}

Keywords: cryptocurrencies, Blockchain, market capitalization, digital wallet, statistical analysis

JEL classification: G21

\section{Introduction}

Over the last few years, an increasing number of the world's population is investing in the cryptocurrency market. Cryptocurrencies are generated through the data mining process. Using the computers and graphical cards, as well as complex mathematical algorithms, a certain value expressed in cryptocurrencies are created (Voras, 2017). In each currency system, a certain set of rules needs to be established to control a level of supply and to impose the safety measures to protect the frauds within the system. Likewise, the paper (traditional) money supply is regulated by the central banks; the supply of the cryptocurrencies is controlled by the set of safety measures imposed within the system. The only difference is that the cryptocurrencies do not use the authority of the central banks, and are not covered by the natural goods. The cryptocurrency units called "coins" are used to save and transfer the values between network users. "Coins" have the same function as the paper money and are used to buy other cryptocurrencies, goods, and services. They can also be used to transfer money to other people. The value of the coins is saved in "online wallet," which is the software wallet stored in the computer or in the mobile device.

The aim of the paper is to compare the most influential cryptocurrencies based on the price and the purchase volume. The main goal of the work is to analyze the 30 most influential cryptocurrencies based on the price, and market capitalization spanned from 2014 to the 2019 year and to determine which cryptocurrency is dominant compared to others. 


\section{Literature review}

The interdisciplinary study area of the cryptocurrencies is relatively new. The general introduction to the crypto economy, Bitcoin and cryptocurrencies were showed by Antonopoulos (2017), Narayanan et al. (2016) and Judmayer et al. (2017). Technical analysis of the Bitcoin's role in the financial market and the investment effectiveness was conducted by Buterin et al. (2015). They concluded that the price of Bitcoin would be dropping, so there will be no payback. Consequently, there is neither opportunity for a good investment nor a possibility for preserving the value of the money, but a reliable and cheap way of transferring the money will remain. Nahorniak et al. (2016) considered a law regulation of the Bitcoin and noticed no existence of any type of regulation on the cryptocurrency market. They suggested new legislation that will consider the virtual currencies as well as the establishment of the committee for crypto economy supervision. Čičin-Šain (2017) found out that the "Croatian income/profit tax system is adequate to accommodate all the tax problems regarding the taxation of the transfer of BitCoin and therefore there is no need to adopt a new regulation". Maček et al. (2017) researched the safety aspects of the Bitcoin IT network and concluded that in comparison with e-banking or m-banking as well as with all the aspects of e-commerce, Bitcoin is the least important for the stable IT business". Turudic et al. (2017) considered the usage of the cryptocurrencies in international exchange business and concluded that "the Blockchain has limitless applications in the international exchange business and consequently there will be more and more companies that will internally use the Blockchain technology for the international exchange business".

\section{Definition and the properties of the cryptocurrencies}

The most commonly used definition of the cryptocurrencies is the one used by the European Central Bank (ECB) which defined such currencies as a "form of unregulated digital money, usually issued and controlled by its developers and used and accepted among the members of a specific virtual community" (Houben et al., 2018). First, in order to avoid any kind of misunderstanding, the terms of electronic and digital money (cryptocurrencies or virtual currencies) need to be clarified.

According to ECB definition, electronic money (e-money) is broadly defined as "an electronic store of monetary value on a technical device that may be widely used for making payments to entities other than the e-money issuer. E-money products can be hardware-based or software-based, depending on the technology used to store the monetary value. In the case of hardware-based products, the purchasing power resides in a personal physical device, such as chip cards or hard disks placed in the personal computers or servers. Monetary values are typically transferred by means of device readers that do not need real-time network connectivity to a remote server. Software-based products employ specialized software that functions on common personal devices such as personal computers or tablets. To enable the transfer of monetary values, the personal device typically needs to establish an online connection with a remote server that controls the use of the purchasing power. Schemes mixing both hardware and software-based features also exist.

The clear insight into the terms of electronic money and digital money (cryptocurrencies or virtual currencies) is presented in Table 1. Expectedly, the only common characteristic is the fact that both types of money are given in the digital form. There is a substantial difference in all other characteristics. For example, the electronic money units are the real currencies issued by the central banks that exist in the form of the coins or banknotes (for example, US dollars (USD), euros (EUR) and 
British pounds (GBP). On the other side, digital money is the imaginary currency having no form in the coins or the banknotes (the most famous example is the Bitcoin).

Table 1

The comparison of electronic and digital money

\begin{tabular}{lll}
\hline & Electronic money & Digital money \\
\hline Form of the money & Digital & Digital \\
Unit value & Traditional values & Imaginary values \\
Legal status & Regulated & Unregulated \\
Acceptability & Wider than the issuer itself & Inside the virtual community \\
Issuer & Legal institutions & Nonfinancial private firms \\
& for electronic money & \\
Money supply & Fixed & Not fixed \\
Repurchase possibility & Guaranteed & Not guaranteed \\
Supervision & Yes & No \\
The type of risk & Mainly operational & Legal, operational, credit, liquidity \\
\hline
\end{tabular}

Source: Zemunik (2016)

Overall, the cryptocurrencies are internet based digital currencies based on the cryptography (cryptology) that can be considered as a digital equivalent of the traditional (paper) money. There are a few facts regarding the cryptocurrencies that can be emphasized: (1) Comparing with all other traditional currencies; the cryptocurrencies are not issued, regulated or controlled by the central banks (Peer to peer system). Only the mechanisms incorporated in the system are the guarantees to maintain the stability; (2) In the case of misusage (counterfeit) of the information in the network, it would be necessary to counterfeit the data that are encrypted repeating the process in all data within the chain and performing the incorrect change in all servers. The experts believe this is impossible; (3) since cryptocurrencies bring radical innovations, they are characterized by significant instability; (4) Cryptocurrencies are exchanged for the real currencies on the stock market where the exchange rate depends on demand and supply ratio (Sajter, 2018).

Since 2013, when the web page CoinMarketCap has been founded to cover all daily transactions, the market capitalization increased from \$1.5 billion USD to almost $\$ 800$ billion USD.

Currently, there are 1100 cryptocurrencies listed on the market. Among all of them, Bitcoin is a leader. It can be clearly seen that Bitcoin has the largest market capitalization of $\$ 279825822710$, while other cryptocurrencies are far behind. The price of Bitcoin rose above $\$ 16.000$ after the currency was split up on Bitcoin and newly developed Bitcoin cash which was introduced on Aug 1, 2017. On Dec 14, 2017. Bitcoin has the largest trade of $\$ 13514600000$ in the last 24 hours. In addition, on Apr 3,2019 , the value of Bitcoin was increased by more than 15 percent in the last 24 hours.

This is a remarkable jump in price, and it has not been seen during the last year. Although unexpected jumps of the cryptocurrency's prices are not something new on the market, such a big change of the price was not seen after the price of Bitcoin decreased by $75 \%$ at the beginning of 2018 . 
Figure 1

The Market Dominance of Bitcoin

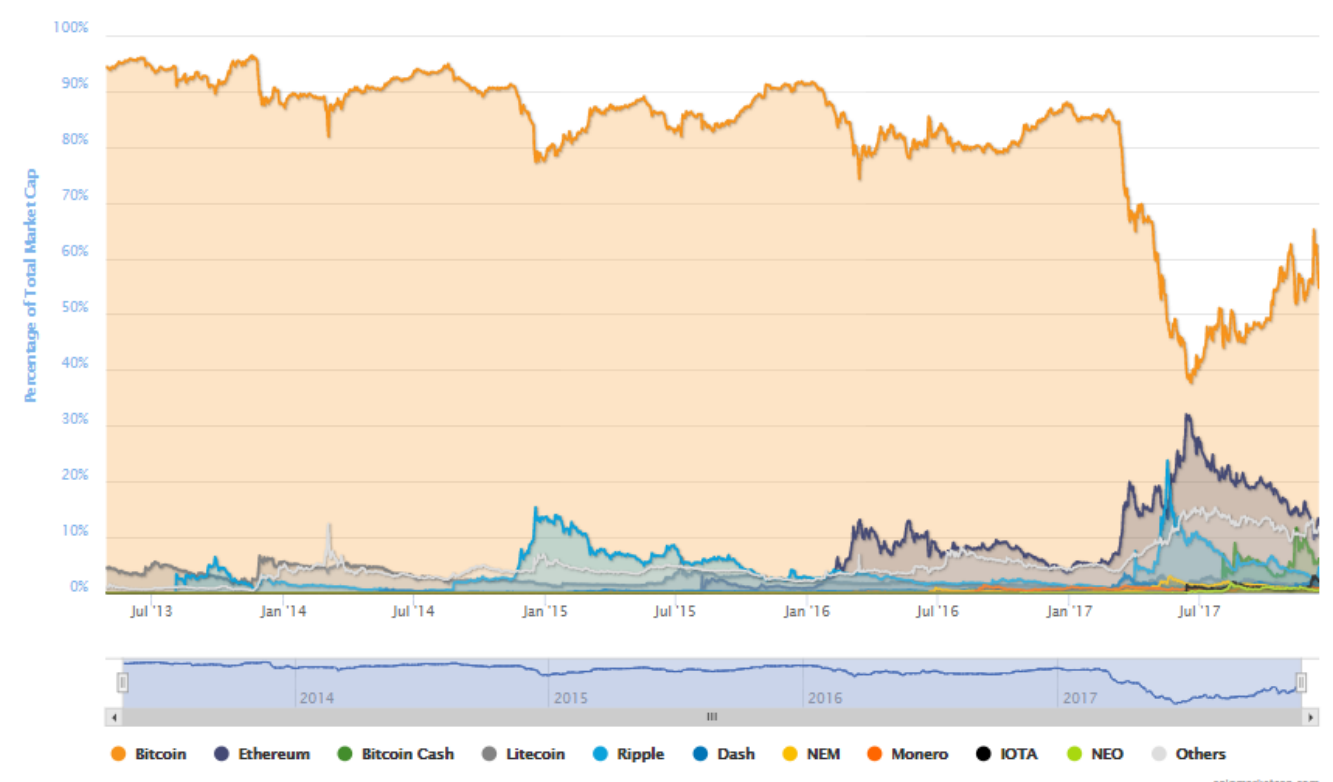

Source: Authors' illustration according to CoinMarketCap (2019)

Additionally, one of the main characteristics of the cryptocurrencies is anonymity. Considering the bank system, this is a grey area since the anonymitiy brings a possibility for illegal activites. In addition, a lack of institutions responsible for the management and control of transactions is present. Since there is no regulation, cryptocurrencies enable a high level of privacy. Consenquently, some countires banned their usage. In spite of exceptional price volatility, the inventive design of the Bitcoin, including the possibility for a quick profit and usage of newly developed interesting technology, still attracts a huge number of users.

The basic idea of the cryptocurrencies is an establishment of the financial system with no financial institutions such as the central banks whose main role is to preserve the value and stability of money. Cryptocurrencies are entirely digitally created, and their usage is based on confidence in mathematical algorithms and cryptology. Even though they are called currencies, and tend to overtake the role of the traditional money, they do not fulfil any of the roles the traditional money takes in real life. In general, the traditional money is widely accepted as an exchange value, which reflects the system of values and represents a tool that can be used to preserve the value through the time. On the other side, the cryptocurrencies are just temporary measure of the value, which due to the strong volatility, are not recommended for long-term investments. There is no consensus regarding the specific changes that would enable the faster process of transactions in Bitcoin system, so there is an increasing number of newly developed cryptocurrencies on the market, which are trying to use the limitations of the Bitcoin as well as the lack of law regulation. In general, it is wise to raise a question if there is a need for a high number of cryptocurrencies in the world economy.

\section{The history of the cryptocurrencies}

The history starts in 2008 when the article entitled "Bitcoin: A Peer-to-Peer Electronic Cash System" was published. The name Bitcoin can be used for the cryptocurrency as 
well as for the network in which Bitcoin functions. The whole project is conceived by the person called Satoshi Nakamoto (the name used by the pseudonymous). The main idea was to create a secure and stable currency in order to obtain full control over the personal finances with no interferrence of the central institutions. In addition, he also incorporated projects such as "bMoney" and "HashCash" (electronic pay system) previously created. The development of digital money is motivated by the idea to retain all the advantages of traditional money and to remove all the disadvantages of it at the same time. The main advantages of the paper money are: "universal acceptance, buyer anonymity, simplicity of verification, the possibility of the non-existence of a bank account, and busines ability and easiness of transportation". On the other side, the main disadvantages of the paper money are: "the possibility of counterfeits, difficulties in transportation of the larger amounts, high expences of distribution and production, limiting a number of nominations and existence of more than one currency" (Dorn, 1997).

In addition, one of the innovations is the usage of a distributed system called "Proof of work" algorithm. Proof-of-work alogrithm is developed, combining two ideas. The first idea is one that proves that for a confirmation of the transaction computer power is needed. The second one is that the user needs to be awarded for participation in the process of the confirmation of the transactions. The award is used as a motiavation to the users for being included in the process.

Figure 2

The Increase in the Bitcoin Price from Apr 28, 2013. until Dec 14, 2017.

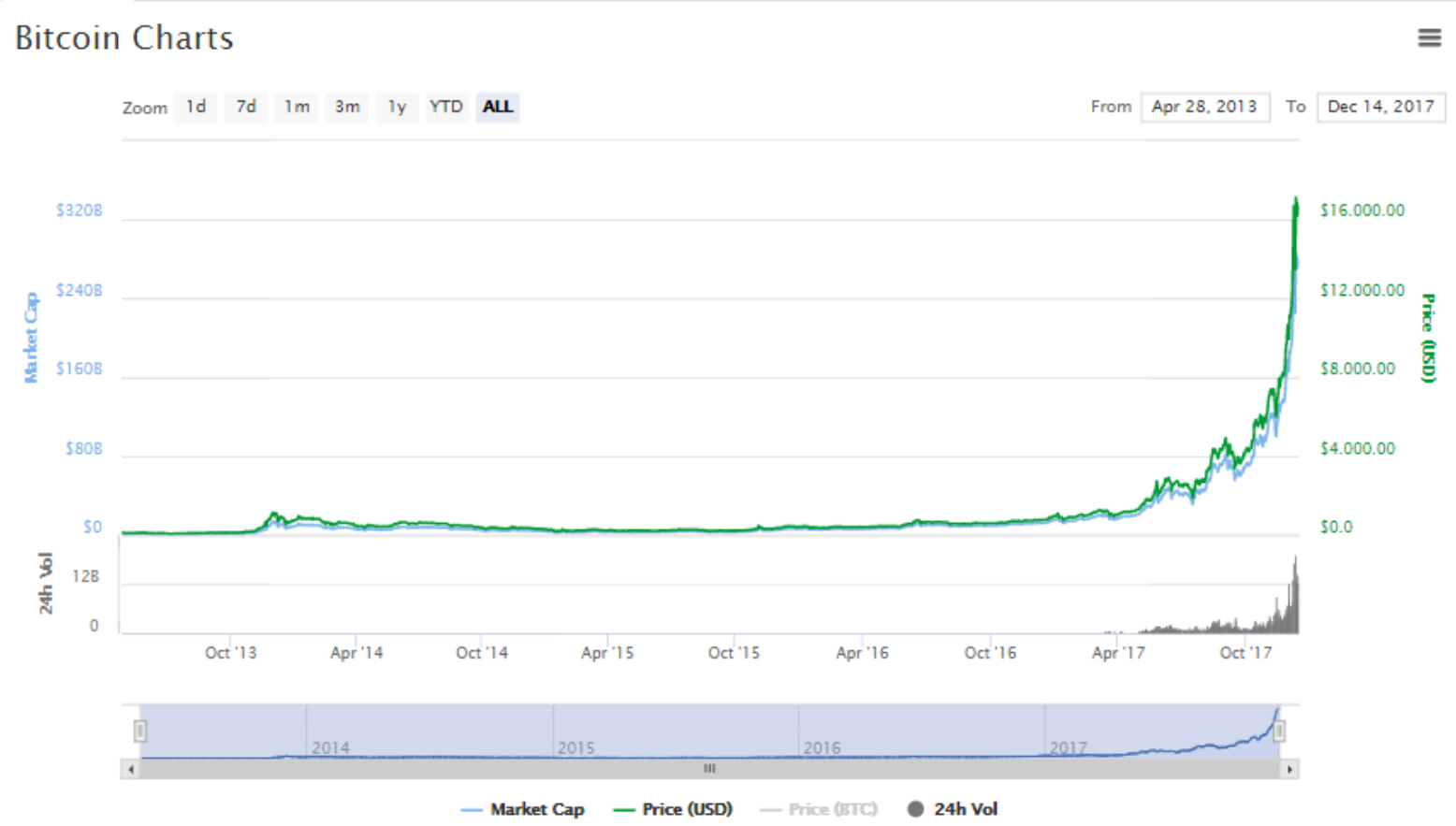

Source: Authors' illustration according to CoinMarketCap (N/A)

It is already mentioned that one of the biggest innovations within the system of cryptocurrencies is Blockchain technology. Blockchain is a special type of database, a "distributed" one, meaning the data is stored on thousands or millions of computers all over the Internet, and a more-or-less immutable one: everyone with the correct software can only add data to the Blockchain, continuously and at the same time. There is no special central authority, which decides which data gets in, only a set of 
rules and algorithms, which govern which data is acceptable. In the case of cryptocurrencies, these rules create the notion of something, which has the properties of money (Voras, 2017).

It is believed that the first transaction was made in May 2010, a person called Laszlo Hanyecz posted on the Internet forum that he wants to buy two Pappa John's pizzas in exchange for bitcoins. Hanyecz offered 10000 bitcoins for two pizzas. The interesting story is that today, the value of his software wallet containing bitcoins would be $\$ 160$ 000 0000. This transaction opened a new path for all the transactions, which take place today on cryptocurrency financial market (Sablak, 2013). The cryptocurrencies introduced after Bitcoin (altcoins) have different parameters. The Ethereum system aims to be a platform for decentralized applications of various uses. Specifically, Bitcoin can be considered as a specialized, strictly dedicated decentralized application - a payment application, as well as a payment system and digital money. Ethereum is designed as a universal platform for deploying decentralized applications - both payment and other applications (current examples could be identity management applications, games, crowdfunding, social networks, prediction markets, lotteries, etc.).

In 2015, European Central Bank (ECB) tried to answer the question of why there is such a huge number of cryptocurrencies today if Bitcoin still dominates the market so strongly. According to European Central Bank (2015), the possible reasons behind this massive launch of decentralized bi-directional virtual currencies include: (1) improving some of Bitcoin's weaknesses (e.g. a higher speed of transaction validation, better energy efficiency and a more robust algorithm); (2) supplying mining alternatives to the existing network of miners (given that Bitcoin mining currently requires specialized computer hardware, suitable rooms to place such equipment in and considerable amounts of energy, including for cooling); (3) offering an alternative for storing value in case Bitcoin experiences problem, such as the (temporary) freezing of withdrawals from wallet providers; (4) profiting from the high attention on virtual currencies in general by setting up a new virtual currency and obtaining a large number of units early on, including by pre-mining (i.e. self-generating the first units before publicly launching the virtual currencies). Furthermore, in the same report ECB states that "despite the inflation of the number of the new cryptocurrencies on the market, this number will be decreasing in the future since most of these cryptocurrencies will become worthless." In the end, only those that will develop a certain resistance to difficulties that Bitcoin has faced will survive (Zemunik, 2016).

\section{Methodology}

In order to reach the main purpose of the paper, empirical research was conducted using the data from Coinmarket. in this analysis are market capitalization and prices of the 30 most influential cryptocurrencies over the period of time 2017 to 2019 with the emphasis on Bitcoin.

However, descriptive statistics are used, and trend analysis has been performed, supported by SPSS version 20. Components of the time series can be analyzed by using the statistical methods. Despite the unfriendliness toward the statistical methods and techniques in the analysis of the cryptocurrencies, one of the dominant rules is the statement: "Trend is your friend." The trend is a long-term tendency that shows the development of a certain occurrence over time. In other words, it is an upwards or downwards shift in a data set over time. In a cryptocurrency market analysis, trends are the tendencies of the price movements.

It is considered, that the best option is to trade in the direction of the trend, therefore, if the market has an upward trend, the traders must be very careful if they 
trade from a position that requires the change of the trend (Hrvatski Bitcoin Portal, N/A). Time series can be stationary or can have a trend. If the time series contains a trend, that means that data series has a long-term tendency to go up or down. The trend can obtain various patterns that describe a certain occurrence. Linear trend estimation expresses data as a linear function meaning an occurrence is changed for approximately the same absolute amount in each unit of the time. If a dynamic time series is used, it is possible to create and analytically express in a proper way a longterm tendency of the development of the occurrence over time. The trend is expressed as a function of time using a model with estimated parameters:

$$
\hat{y}_{t}=a+b x_{t}
$$

There is a possibility to apply this model as a forecasting tool as well. The application of the linear trend takes into account that the future will be similar to the past. This method is not suitable if the occurrence exhibits significant irregularities. It is reliable only for shorter periods. However, had this "trend" been projected forward a few years, the resulting forecasts of the future sales would have been highly inaccurate. When we look at the picture in future years that we see just how inappropriate a fixedtrend model would have been. For business and economic data, another treatment of the regular components of a time series is preferable. Rather than regarding them as being fixed for all time, it is generally more sensible to think of them as steadily evolving over time. Thus, we need not be committed to fixed trend or seasonal patterns but can allow for the possibility that these components change with time. (Newbold et al., 2010).

\section{Results}

Analysis of the cryptocurrency movements on the financial market is focused on market capitalization as well as on market prices of the 30 most influential (traded) cryptocurrencies over the time 2017 to the 2019 year.

Table 2 represents descriptive statistics indicators of the market capitalization of the 30 most influential cryptocurrencies. It can be concluded that the mean market capitalization quoted in American dollars (USD) in 2017 was \$567 130 553.7, in 2018. \$24 710672 704, while in 2019 grew up to $\$ 2.12$ billion. Half of the thirty listed cryptocurrencies in 2017 had a minimal market capitalization of \$20 235409 or less, while the remaining half of the listed cryptocurrencies had a minimal market capitalization of $\$ 20235409$ or more. In 2018 the median was \$6 011 491 582, while in 2019 was $\$ 667$ million. The minimal market capitalization observed in 2017 was $\$ 7896$ 004 (Emercoin), while maximal market capitalization in the same year was \$14876057 730 (Bitcoin). In 2018 that minimum was \$1 713710709 (Dogecoin), while a maximum of $\$ 287582315011$ was reached by Bitcoin. In 2019 the minimal market capitalization was $\$ 202598950$ (Zilliqa), and the maximal capitalization is kept by Bitcoin yielding $\$ 71206795853$.

A comparison of standard deviations was appropriate to determine which asset was riskier. The largest standard deviation of the market capitalization was noticed in 2018, and it gives $\$ 57347642673$, compared with the data obtained in 2017 of $\$ 2707$ 385504 , and $\$ 3.95$ billion in 2019. Therefore, the market capitalization exhibits a big variability, which makes arithmetic mean very unreliable. 
Table 2

Descriptive Statistics of the Market Capitalization of the 30 Most Influential (Traded) Cryptocurrencies for 2017, 2018, and 2019 Year (Quoted in USD).

\begin{tabular}{lccc}
\hline & $\begin{array}{c}\text { Market } \\
\text { Capitalization } \\
\mathbf{8 . 1 . 2 0 1 7 .}\end{array}$ & $\begin{array}{c}\text { Market } \\
\text { Capitalization } \\
\mathbf{8 . 1 . 2 0 1 8 .}\end{array}$ & $\begin{array}{c}\text { Market } \\
\text { Capitalization } \\
\mathbf{6 . 1 . 2 0 1 9 .}\end{array}$ \\
\hline Mean & 567130553.7 & 24710672704 & $2.12 \mathrm{E}+09$ \\
Median & 20235409 & 6011491582 & $6.67 \mathrm{E}+08$ \\
Standard Deviation & 2707385504 & 57347642673 & $3.95 \mathrm{E}+09$ \\
\hline
\end{tabular}

Source: Authors' work according to CoinMarketCap (N/A)

Descriptive statistics showing the results of the market prices quoted in American dollars (USD) presented in Table 3, indicating that the mean price of the 30 most influential cryptocurrencies in 2017 was $\$ 213.52$, in 2018 was $\$ 542.52$, and in 2019 , it yields $\$ 176$. 79. Median of the 30 listed cryptocurrencies in 2017 was $\$ 3.64$, in 2018 was $\$ 92.35$, and in 2019 was $\$ 2.62$. There is a strong tendency in the market prices fluctuation. The minimal market price observed in 2017 was $\$ 1.01$ (NuBits), while the maximal market price was $\$ 2974.9$ (Bitcoin). In 2018 the minimal market price was $\$ 11.79$ (Hshare), while the maximal market price was $\$ 9096.13$ (Bitcoin). In 2019 the minimal market price was $\$ 0.002328$ (Dogecoin), and the maximal market price was $\$ 4076.63$ (Bitcoin). Comparing the data, it can be seen that the largest deviation from the average price was in 2018, and it reached $\$ 57347642$ 673. Comparing variation using the standard deviation, in this case, would be misleading.

\section{Table 3}

Descriptive Statistics of the Market Prices of the Most 30 Influential (Traded) Cryptocurrencies for 2017, 2018 and 2019 Year (Quoted in USD)

\begin{tabular}{lccc}
\hline & Market & Market & Market \\
& Prices & Prices & Prices \\
& $\mathbf{8 . 1 . 2 0 1 7 .}$ & $\mathbf{8 . 1 . 2 0 1 8 .}$ & $\mathbf{6 . 1 . 2 0 1 9}$ \\
\hline Mean & 213.52 & 54.52 & 176.79 \\
Median & 3.64 & 92.35 & 2.62 \\
Standard Deviation & 618.73 & 1654.87 & 743.48 \\
\hline
\end{tabular}

Source: Authors' work according to CoinMarketCap (N/A)

Based on the analysis presented in the above table, Bitcoin still keeps the leading position among all the cryptocurrencies currently listed on the market. The price of Bitcoin is almost ten times bigger than the price of Maker, which keeps the second position during the last two years. The biggest price jump Bitcoin was having from Apr 2017 to Oct 2017 when it reached a psychological price point of $\$ 20000$. As far as the market, capitalization is concerned, only Ethereum closely approached Bitcoin in July 2017 but just for a short period. The same pattern happened in 2019. Currently, there exists certain stability on the cryptocurrency market. It can also be noticed that almost all the cryptocurrencies are losing their values. Considering that Bitcoin is ultimately the most influential cryptocurrency on the market today, (Bitcoin dominance on July 9, 2019. was $64 \%$ of the total market capitalization \$352 505516548 ), a linear trend model for Bitcoin market capitalization covering the period from 2014 to 2019 is calculated using the estimated parameters. As expected, the results show that the Bitcoin market capitalization in this time has a tendency of growth, and it is growing on average for \$32 627707989 per year. A strong oscillation is present during the 2018 
year. Nevertheless, it would be desirable if the trend line reliability indicator for this model is bigger ( $R$ Square $=0.31836127$ ), which would certainly improve the business decision-making process. In the linear model trend for Bitcoin market prices, average growth of the price of the Bitcoin is $\$ 1852.482$ per year. This model is even less reliable, which can be verified by noting that $R$ Square $=0.298476$. In conclusion, the claim that the trend is the best statistical indicator of directional movement tendency, from the statistical point of view, is not conclusive.

A head and shoulders pattern, in technical analysis, is one of several top patterns that signal, with varying degrees of accuracy, that an upward trend is nearing its end. The head and shoulders pattern forms when a stock's price rises to a peak and subsequently declines back to the base of the prior up-move. Head and shoulders patterns can also signal that a downward trend is about to reverse into an upward trend. In this case, the stock's price reaches three consecutive lows, separated by temporary rallies. Of these, the second trough is the lowest (the head) and the first and third are slightly shallower (the shoulders). The final rally after the third dip signals that the bearish trend has reversed and prices are likely to keep moving up. This is mostly a pattern that indicates a "reversal" of the trend and the price goes in the opposite direction (Hrvatski Bitcoin Portal, N/A) when the application of exponential trend is recommended in order to analyze the cryptocurrency movements.

\section{Conclusion}

Crypto economy is characterized by a significant difference from other financial markets. It includes cryptocurrencies that are exceptionally volatile with almost the same probability of a huge yield or equally likely a huge loss. The results show extremely high variability of the prices of the cryptocurrencies, and this variability is not largely connected with the price movements on other standard financial markets. Anyway, the invention of cryptocurrencies, especially the usage of Blockchain technology, are changing our perception of traditional money. In addition, the cryptocurrencies contributed to innovations and insights into the unknown areas of the financial markets. They enabled a huge amount of people to participate in this market, start a trade, and invest their money with minimal efforts or knowledge. Unfortunately, this can cause various forms of deviated patterns known as "Pumps \& Dumps". On this market, it is equally easy to lose or gain. Based on this work, it is possible to confirm that Bitcoin is the most influential cryptocurrency on today market. As far as market capitalization, Ethereum got close to Bitcoin in July 2017 and later in 2019, but just for a short period. At this moment, there exists a certain stabilization of the market, and almost all the cryptocurrencies decreased in their values. There are numerous debates regarding the potential risk connected with these types of investments. Some group of people shares the opinion that the investment in this market is a just loss of money in the end due to the problems within the system, while the other group solely uphold the whole concept in which they see a huge financial opportunity. By the results of research, it is possible to conclude that the world cryptocurrency market is improved day-by-day using a small correction twice a year. Since 2013, when the web page CoinMarketCap has been founded to cover all daily transactions, the market capitalization increased from $\$ 1.5$ billion USD to almost $\$ 800$ billion USD. The growth is undeniable, but still, there are a lot of questions to be answered.

It is very hard to make any conclusions regarding the future of Bitcoin as well as the future of other less known and less represented cryptocurrencies. The invention and development of Bitcoin was a revolution in the financial world, but still, there is a problem regarding the limiting number of Bitcoins in the system. How will it move forward once the maximum number of Bitcoins is produced? is it worthwhile to 
produce a currency that cannot become a regular exchange value in everyday life? Is the Bitcoin already an "old story" since there are other socalled "Tokens" or "Alts" that can be used in everyday life today? All these questions are legitimate, but one fact is sure: the invention of Bitcoin and its concept with accompanying technology opened a completely new world. The idea of decentralization in which everyone is a personal banker brought numerous benefits or will eventually bring them in the future. In that sense, it could be enough that just a couple valuable concepts originated from the idea of Bitcoin such as reliable and cheap transfer of the money for numerous people who do not owe a bank account. Further effects of the invention of the cryptocurrencies and their usage will be a focus of some subsequent research.

\section{References}

1. Antonopoulos, A. M. (2017), Mastering Bitcoin: Programming the Open Blockchain, 2. edition, O'Reilly Media, Inc., Sebastopol, CA, USA

2. Buterin, D., Ribarić, E., Savić, S. (2015), "Bitcoin - nova globalna valuta, investicijska prilika ili nešto treće?", Zbornik Veleučilišta u Rijeci, Vol. 3, No 1, pp. 145-158.

3. CoinMarketCap (N/A), available at: https://coinmarketcap.com/ (3 April 2019).

4. Čičin-Šain, N. (2017), "Oporezivanje bitcoina", Zbornik Pravnog fakulteta u Zagrebu, Vol. 67, No. 3-4, pp. 655-693.

5. Dorn, J. A. (1997), The future of money in the information age, Cato Institute, New York, USA.

6. European Central Bank (2015), "Virtual currency schemes - a further analysis", available at: https://www.ecb.europa.eu/pub/pdf/other/virtualcurrencyschemesen.pdf (3 April 2019).

7. Houben, R., Snyers, A. (2018), "Cryptocurrencies and Blockchain", available at: http://www.europarl.europa.eu/cmsdata/150761/TAX3\%20Study\%20on\%20cryptocurr encies\%20and\%20blockchain.pdf (28 June 2018).

8. Hrvatski Bitcoin Portal (N/A), available at: https://crobitcoin.com (23 March 2019).

9. Judmayer, A., Stifter, N., Krombholz, K., Weippl, E. (2017), "Blocks and Chains: Introduction to Bitcoin, Cryptocurrencies, and Their Consensus Mechanisms", Synthesis Lectures on Information Security, Privacy, \& Trust, Vol. 9, No. 1.

10. Maček, D., Alagić, D. (2017), "Comparisons of Bitcoin Cryptosystem with Other Common Internet Transaction Systems by AHP Technique", Journal of Information and Organizational Sciences, Vol. 41, No. 1, pp 69-87.

11. Nahorniak, I., Leonova, K., Skorokhod, V. (2016), "Cryptocurrency in the context of the development of digital single market in European union", InterEU Law East: journal for the international and european law, economics and market integrations, Vol. 3, No. 1 , pp. 107-124.

12. Narayanan, A., Bonneau, J., Felten, E., Miller, A., Goldfeder, S. (2016), Bitcoin and Cryptocurrency Technologies: A Comprehensive Introduction, Princeton University Press.

13. Newbold, P., Carlson, W. L., Thorene, B. (2010), Statistics for business and economics, Mate, Zagreb.

14. Sablak, T., (2013), "New Private Currencies Like Bitcoin Offer Potential — and Puzzles", Econ focus, third quater, pp. 18-27, available at: https://www.richmondfed.org/ /media/richmondfedorg/publications/research/econ focus/2013/q3/pdf/featurel.pdf (30 June 2016).

15. Sajter, D. (2018), "Financijska analiza kriptovaluta $\cup$ odnosu na standardne financijske instrumente", available at: https://bib.irb.hr/datoteka/930275.Interkat_2018_kripto.pdf (10 April 2019).

16. Turudić, D. A., Milić, J., Štulina, K. (2017), "Korištenje kriptovaluta u međunarodnom poslovanju", Zbornik sveučilišta Libertas, Vol. 1-2, No. 1-2, pp. 191-210, available at: https://hrcak.srce.hr/191294 (15 March 2019).

17. Voras, I. (2017), The Sceptic's guide to Bitcoin, Cryptocurrencies and the Blockchain, Independent Pub. 
18. Zemunik, D. (2016), Utjecaj virtualnih valuta na politiku centralnih banaka, Sveučilište u Splitu, Ekonomski fakultet, Split.

\section{About the authors}

Višnja Jurić received Ph.D. 2019 from the University of Ljubljana, School of Economics and Business, interdisciplinary doctoral program Statistics, on thesis "Asymmetric double Weibull distribution and its applications". She is mathematics and statistics instructor at University College "Effectus, for Law and Finance, Croatia. MSc in applied mathematics has from the "University of Nevada", Reno, USA. She completed this program in 2003, and then subsequently taught College Algebra at the Art Institute of California in San Francisco. In 2004, she was enrolled at a Ph.D. program in Statistics at the "University of California, Santa Barbara", but returned to Croatia in 2006. The author can be contacted at vjuric2000@yahoo.com.

Vanja Šimičević is Associate Professor and Scientific Adviser at the University of Zagreb, University Department for Croatian Studies, teaching Multivariate Statistical Methods, Statistics in Social Sciencies. She received a Ph.D. from the University of Zagreb, Faculty of Economics and Business in the area of quantitative economics (1999). Her major area of research is focused on applications of quantitative methods, particularly statistical modeling techniques and analysis, in the field of business, economic and other social sciences, using a wide range of statistical methods and techniques, and on those topics, she published a number of papers in international and national journals. Her scientific work is a significant contribution to the application of modern statistical methods in social sciences using a wide range of statistical methods and techniques. The author can be contacted at vsimicevic@hrstud.hr.

Domagoj Kajba graduated at "Zagreb School of Economics and Management", Zagreb, Croatia. His research interest is focused on cryptocurrencies. The author can be contacted at dkajba@zsem.hr. 